\title{
The trouble with academic reading: exposing hidden threshold concepts through academic reading retreats
}

\section{Angela Rhead}

Keele University, UK

\section{Abstract}

Acknowledged as a troublesome threshold concept for students and teachers alike in higher education ( $\mathrm{HE})$, academic reading persists as a significant yet under-investigated challenge. This paper introduces an exciting teaching innovation launched in 2017 at Keele University to meet that challenge: academic reading retreats. Adapting a writing retreat format, they deliver a range of strategies for reading journal articles and provide opportunities for private practice and shared reflections, which can facilitate deep learning about complex epistemological concepts. They open a dialogue within the academic community that helps students better understand the relationship between reading and enquiry, and helps academics better understand their students' reading challenges. This case study provides a brief literature review and personal reflections about facilitating student reading, an introduction to our academic reading retreats and a preliminary evaluation of their potential. It concludes with a recommendation for extended time and space for academics and students to explore academic reading together, alongside an acknowledgement of the challenges that entails.

Keywords: academic reading; higher education.

\section{Background}

\section{The trouble with reading}

The author's experience as a lecturer and learning developer has highlighted the poor academic reading practices of many undergraduates and postgraduates alike. In particular, they report reading journal papers difficult, frustrating, perplexing or simply 
'boring'. This troubled relationship with the purpose and process of academic reading presents a significant barrier to learning at university that is reflected in pedagogical scholarship. Practical sources offer technical strategies to develop or remedy students' skills (Cottrell, 2013; Wallace and Wray, 2016); theoretical scholarship focuses on the disciplinary context of academic literacies, 'academic socialization' (Lea and Street, 1998; Christie et al., 2014), or the underlying causes of the apparent deficit, drawing on concepts of social or cultural capital that point to HE's capacity to share cultural capital (Hockings, 2010; Morgan and Houghton, 2011; Hannon et al., 2017). However, practical and scholarly sources both attend primarily to writing, with the role of reading in academic thinking still largely subordinated to its written performance (McAlpine, 2012), and with reading cast as 'other literacy practices' (Lea and Street, 2006, p.376).

All sources concur, however, that we face students holding common misconceptions: Firstly, about the purpose of academic reading, why we do it, e.g.: 'I've written my essay, I just need to find the references to back it up'. This captures a fundamental misunderstanding of purpose, where students use reading as a way to support preconceived ideas rather than understanding emerging from and through reading (Brewerton, 2014; McAlpine, 2016). Similarly, reports of academic papers being 'boring' indicate a common misunderstanding of the function of journal articles in the academic community to introduce new knowledge, and the application of historical experiences of reading (Papen and Theriault, 2017) that retain expectations of sequential unveiling of meaning: 'Ta dah!'. Secondly, this epistemological misconception of purpose is often complemented by a lack of confidence in the process of academic reading itself: how we do it (Shon, 2012; Wallace and Wray, 2016). Students report reading the same pages repeatedly, or 'getting lost', and these learning troubles regarding handling and interpreting academic papers in particular are observed at undergraduate, postgraduate and doctoral levels.

Equally, academics report teaching troubles with high aspirations for their students' learning, but repeated disappointments with an apparent reluctance to read more broadly (Saltmarsh and Saltmarsh, 2008; Weller, 2010; Hallett, 2013). This concern is well founded, with reading essential for learning discipline-specific threshold concepts (Meyer and Land, 2003 and 2005; MacMillan, 2014), but also in itself an epistemological conceptual threshold (Wisker and Robinson, 2009) that learners in higher education 
need to navigate, with critical reading and the function of journal papers having a crossdisciplinary significance for academic enquiry. How to 'get' students to read remains a persistent conundrum, particularly where understanding is reached through the synthesis of combined reading in order to reach a position (McAlpine, 2016). Moreover, whilst the range of disciplines hold differing views of criticality (Moore, 2013), all seem to share a common concern about the quality of reading students are engaged in. Academic reading then, seems persistently troubling for academic staff and students alike. Both appear frustrated by a largely private and complex practice that seems hard to pin down, but with limited time and space in the curriculum to address deep seated, often tacit, misconceptions and misunderstandings.

Many universities attempt to address academic skills through extra-curricular interventions and central support services that deliver remedies (Lea and Street, 1998; Wingate, 2006): symptoms of scant or uncritical reading diagnosed as a student's lack that sits outside the discipline. Discipline outsiders, such as learning developers, librarians or other third-space professionals (Veles et al., 2018) are tasked with teaching, for the most part generic writing and, less frequently, reading skills through programme events or extracurricular workshops and tutorials. Both strategies, however, place responsibility for translating these generic concepts to specific disciplinary enquiry, with the student. Hallett (2013) argues that both skills-focused and learner-focused concepts of support are problematic precisely because they sit outside the discipline, and points to a third concept that views support in terms of the literacy practices of particular academic communities. This supports the view that academic 'skills' must be embedded within a discipline as part of a holistic and inclusive learning experience rather than an explicit intervention (Morgan and Houghton, 2011; Hill and Tinker, 2013). However, these embedded approaches do not automatically engage with Hallett's third concept and may still take the form of a technical, uninterrogated delivery of skills, rather than underpinning a 'connected curriculum' (Fung, 2017) focused on research and scholarship. Equally, a curriculum-embedded but assessment-driven approach does not automatically embrace the critical view of an academic communities' practices advocated in Lea and Street's (1998) widely supported academic literacies model.

Having explored discipline-specific approaches to developing students' academic reading practices in programmes and extra-curricular workshops, I remained frustrated both by the 
lack of time required for the deep learning (Marton and Säljö, 1976) necessary to effectively explore the challenging concepts about the purpose of academic reading in enquiry, and journal papers in particular, alongside the technical process of handling papers. Even in longitudinal learning over several weeks, learning remained rushed and surface; lengthy embedded sessions remained persistently (mis)directed towards assessment, with learning strategic and contained. A new strategy, which supported deeper learning and allowed for disciplinary content but also engaged with crossdisciplinary concepts of reading as scholarship, seemed increasingly desirable.

\section{Retreats: An emerging solution?}

Research on writing retreats suggests that when they are done communally, participants are able to successfully explore writing identities and develop their own writing practices (Kornhaber et al, 2016; Papen and Thériault, 2017). This chimes with the 'hidden' nature of reading, which echoes writing in that it is often a solitary and private activity, and suggests that communal exposure might act equally positively on reading practices and identities (McAlpine, 2012). Further, writing retreats are inherently purposeful yet diverse, offering a format that supports discipline-specific reading whilst focusing on the crossdisciplinary aspects of academic reading. This suggests that retreats might make space for the deep thinking required to support navigation of conceptual threshold concepts about reading for enquiry (Marton and Säljö, 1976; Wisker and Robinson, 2009). They might also provide an 'imaginative space' (Grant and Knowles, 2010) to develop participants' confidence and identity as academic readers. Finally, local writing retreats based on Murray and Newton's model (2009) are egalitarian affairs, with PhD students, lecturers, teaching fellows and professors alike forming a community of practitioners (Lave and Wenger, 1991; Fung, 2017), submitting voluntarily to a facilitator's control. I wanted to capture this aspect of writing retreats in the academic reading retreats to expose the ubiquity of the challenges, and pleasures, inherent in academic reading as enquiry. I imagined that including academics as readers-in-residence would demonstrate to students participating more 'peripherally' that even those at the centre of our academic community do not merely flick through a journal article to come to a considered and critical understanding.

Consequently, inspired by writing retreats as a way to safeguard precious time and space, but with a structure that ensures discipline and focus (Murray and Newton, 2009), I 
devised and delivered ten academic reading retreats to explore the purpose and process of reading academic journal articles for enquiry. They draw on writing retreats in three ways: firstly, they are organised into significant cycles of delivery, practice and discussion that incorporate private and public phases. Secondly, participants bring one or two journal articles to support their research or assessment, which facilitates disciplinary enquiry. Thirdly, academics and students participate as equals in the retreat, reading, discussing and reflecting together. However, academic reading retreats differ from writing retreats in that they are teaching and learning events in which concepts about enquiry and strategies to perform critical reading are delivered. Additionally, whilst students are learning how to read, academics are also learning how to teach reading. Finally, in the role of the facilitator I am also a teacher, coach and fellow member of the community

\section{Academic reading retreat outline}

Open academic reading retreats are full day events for up to fifteen students and two academics in venues that give a sense of retreating 'for real'. All are invited to participate: UGs, PGTs and PGRs are targeted with emails that explicitly offer support for dissertations and literature reviews; academic staff are emailed with a professional development opportunity to support teaching practices. Both apply, outlining hopes and challenges. Ideally, academics and students come from different programmes, enhancing the interdisciplinary nature of the retreat but also protecting egalitarianism by reducing the sense of hierarchy.

After a reflective task and introduction, the retreat follows three cycles of reading (see Figure 1). The first phase is an introduction to the process of enquiry using the metaphor of 'the stage'. This is a role-play developed to represent the academic community and the function of journal papers in sharing and developing new disciplinary knowledge (Rhead, 2016). It focuses on an article's performance of new knowledge in its disciplinary theatre, whilst simultaneously engaging with discourse already playing out on its stage. It casts articles as persuasive pieces and its readers as an audience of actor-critics. Next, participants individually analyse their paper to locate its position in terms of previous knowledge, its claim, the premises of that claim and its methods. The group then reconvenes to share findings and thoughts. 
The second phase focuses on scrolling and textmapping an article (Middlebrook, 1994) to identify its construction and to deliberately avoid sequential approaches to reading. Creating a scroll with their paper (see Figure 1) and unrolling it for inspection (Abegglen et al., 2019) enables readers to regard it as a whole, to discern the significance of the different sections in formulating and structuring an argument. Participants map their scrolled article individually, then reconvene to share findings and thoughts.

The third phase turns its attention beyond the individual article, moving to a consideration of the references and evidence used to support the paper and the relevance of the paper for participants' own enquiry, including approaches to synthesising sources and developing a literature review. After another reading of their paper, the group reconvenes finally to share thoughts, reflect on the day's learning and outline future actions.

Alongside each silent reading phase I run a parallel clinic where participants can access differentiated support privately, outside the reading room: sometimes, guidance is needed to apply concepts; sometimes, extra challenges for anyone ready to develop a more sophisticated analysis. This has been particularly important where PGR students are participating alongside UGs. 
Figure 1. Academic reading retreat programme.

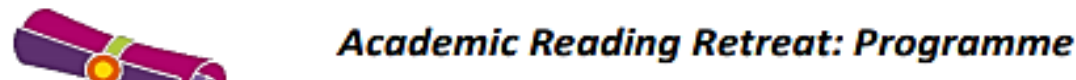

\begin{tabular}{|c|c|c|}
\hline $9: 30$ & \multicolumn{2}{|l|}{$\begin{array}{l}\text { Coffee } \& \text { cake: Welcome (+ last-minute scroll making) } \\
\text { Sharing research / hopes and fears / retreat 'rules' }\end{array}$} \\
\hline $10: 00$ & \multicolumn{2}{|c|}{$\begin{array}{l}\text { The Stage: the purpose of academic journal articles. } \\
\text { Discussion and dramatized enactment of the purpose of journal articles and their relationships } \\
\text { one another. Facilitator presents the importance of the abstract in identifying/justifying : } \\
\text { - The scenery (discourse) } \\
\text { - The space on the stage ('gap') } \\
\text { - The motivation (purpose / audience) } \\
\text { - The method ('how') } \\
\text { Plus, the amplification of the initial 'what' contained in the article's conclusion/discussion: } \\
\text { - Premises of argument / Conclusions from research.. } \\
\text { - Implications (So what? + What else?) }\end{array}$} \\
\hline $10: 30$ & $\begin{array}{l}\text { Read 1: Abstract-Conclusion Worksheet } \\
\text { Participants spend } 60 \text { minutes analysing their abstract } \\
\text { and conclusion. }\end{array}$ & $\begin{array}{l}\text { Drop-in Clinic } \\
\text { Facilitator offers one-to-one advice and } \\
\text { guidance outside the silent reading room. }\end{array}$ \\
\hline $11: 30$ & \multicolumn{2}{|l|}{$\begin{array}{l}\text { Coffee: Review and Reflect } \\
\text { Surprises, challenges, questions. }\end{array}$} \\
\hline $11: 50$ & \multicolumn{2}{|l|}{$\begin{array}{l}\text { Scrolling: mapping the argument } \\
\text { Facilitator demonstrates text-mapping and identifies: }\end{array}$} \\
\hline $12: 00$ & $\begin{array}{l}\text { Read 2: Textmapping } \\
\text { Participants map scrolled articles to identify structure } \\
\text { of argument and (if time) map each section identified. }\end{array}$ & $\begin{array}{l}\text { Drop-in Clinic } \\
\text { Facilitator offers one-to-one advice and } \\
\text { guidance outside the silent reading room. }\end{array}$ \\
\hline $13: 00$ & \multicolumn{2}{|l|}{$\begin{array}{l}\text { Lunch: Review and Reflect } \\
\text { Surprises, challenges, questions. }\end{array}$} \\
\hline $13: 40$ & $\begin{array}{l}\text { Read } 2 \text { continued: Close reading for relevance } \\
\text { Participants choose a section / sections of their scroll } \\
\text { to read/map more closely. } \\
\text { Participants begin to consider the relevance of the } \\
\text { article for their specific enquiry. }\end{array}$ & $\begin{array}{l}\text { Drop-in Clinic } \\
\text { Facilitator offers one-to-one advice and } \\
\text { guidance outside the silent reading room. }\end{array}$ \\
\hline $14: 40$ & \multicolumn{2}{|c|}{$\begin{array}{l}\text { The Web: developing a literature review } \\
\text { Presentation of different strategies to synthesise articles and further reading to develop a cast. }\end{array}$} \\
\hline $15: 00$ & $\begin{array}{l}\text { Read 3: Inspecting cast list and searching for players } \\
\text { Participants begin to mine article's reference list for } \\
\text { further reading and locate the article's position in } \\
\text { relation to other 'players' they have read. }\end{array}$ & $\begin{array}{l}\text { Drop-in Clinic } \\
\text { Facilitator offers one-to-one advice and } \\
\text { guidance outside the silent reading room. }\end{array}$ \\
\hline $16: 00$ & \multicolumn{2}{|l|}{$\begin{array}{l}\text { Coffee: Final Review and Reflect } \\
\text { Surprises, challenges, questions and next steps. }\end{array}$} \\
\hline $16: 30$ & \multicolumn{2}{|l|}{\begin{tabular}{|l} 
END \\
\end{tabular}} \\
\hline
\end{tabular}




\section{Evaluation}

Observation and participant feedback gathering concurs: academic reading retreats are rich learning events that act on academic practice and identity. All our learning development events include an online post-event evaluation form, which collects responses anonymously at source. Participants whose responses are used in this text have been informed that anonymised quotations may be included. Questions include a simple rating scale for the helpfulness of the event in developing academic performance and an opportunity to tell us why, and how, it will impact on behaviours. Over the past two years we have received fifty two responses from ten retreats with an average score of 4.94, where 5 is 'Very useful' and 1 is 'Not at all'.

Student feedback falls into three broad categories. Firstly, when commenting on the process of reading academic articles, they identify practical skills and technical strategies as very useful. Many report that they have learned to 'break-down' or 'take apart' papers, thus increasing their sense of confidence:

It meant whilst reading the actual article I didn't get lost in all the points being made and unable to piece everything together.

This suggests that academic reading retreats can successfully deliver the technical skills of academic reading (Hallett, 2013).

Secondly, student comments suggest that the retreats improve understanding of the purpose of academic reading in supporting enquiry generally, navigating the key conceptual threshold (Wisker and Robinson, 2009) of academic reading, and their research specifically. This indicates that the retreats may also have a deeper impact on their identity as scholars (Papen and Thériault, 2017) and facilitate criticality in regard to epistemology (Lea and Street, 2006):

I now take more time with my academic reading. This time allows me to find more depth within the article rather than just providing myself with a surface level analysis. 
Thirdly, there is evidence that the interdisciplinary and social nature of the event provides a sense of academic community and authenticity that also impacts on the students' identity as academic participants, which supports models of social and collaborative learning (Lave and Wenger, 1991; Lea and Street, 2006; Fung, 2017):

The sharing of a diverse range of ideas led to an increase in learning and a more fruitful grasp of the issues faced when it comes to academic reading.

Academics report learning in terms of gaining a better understanding of the challenges students face, for example:

(I)t has made me reflect on assumptions that I might have made about what students know about how to actively read and what to actively read

Secondly, they report a commitment to practice development:

I definitely need to incorporate reading processes more actively into my module design.

This suggests that academic reading retreats can be a promising form of academic development, encouraging academic teaching staff to consider developing a connected curriculum (Fung, 2017) that moves away from the remedial towards embedded learning development (Wingate, 2006).

Inevitably, there are also challenges raised in running academic reading retreats, chiefly concerning recruitment and logistics. A whole day is both difficult to arrange, in busy student and academic schedules, and to 'sell'. It is also difficult to accommodate in an appropriate venue, with an increasing paucity of learning spaces in HE. The retreats require much preparation, administration and organisation, but by their very nature are limited in scope; they demand high levels of commitment from students, academics and facilitators; they therefore tend to engage those who are already engaged.

\section{Discussion}


In terms of implications for teaching and learning design, two key themes emerge: the importance of 'retreating' with generous time and space and the significance of authenticity. The generosity of time and space afforded in a retreat (Murray and Newton, 2009) enables deep learning and critical reflection on an individual basis: students can explore, retread and navigate the landscape of an article at their own pace and with personalised support. Equally, this generosity enables effective social learning to occur, where shared challenges, passions and cumulative discussion create a temporary community of academic practitioners that exposes shared anxieties and experiences, but also celebrates new understanding (Grant and Knowles, 2010). The authenticity of the participant's enquiry is, I suspect, key to the academic reading retreats' success: whilst the event is technically 'extra' curricular, it is driven by individual interests and research, with each participant bringing journal articles pertinent to current, authentic enquiry (Fung, 2017). This lends support to Lea and Street's (2006) argument that academic reading should not be separated as a generic skill but be seen as inextricably linked to disciplinary knowing. It may also explain the clear establishment of community observed on retreats, since professors and undergraduates alike are engaged in a genuine and common practice. This reflects Lave and Wenger's (1991) model of legitimate peripheral practice in thinking about how newcomers can transition in experience and identity from the modelling offered by those at the centre of the community.

In terms of benefits to a university's academic community, reading retreats have a potential dual role as both academic development and learning development events. For readers-in-residence, the retreat can work on academics' teaching practices, focusing their attention on reading as disciplinary learning. For students, the retreat seems to act on their identity as enquirers, focusing their attention away from the strategic assignment passing and towards the pursuit of deeper understanding. However, there remain conundrums, most of which centre on scalability. How can we increase student numbers at reading retreats and maintain a supply of academic readers-in-residence? Additionally, with increasing numbers of programmes at Keele adopting the academic reading retreat model, how far does the loss of interdisciplinarity, authenticity and generosity of time impact on the benefits?

This preliminary evaluation has led to a funded research project, currently being undertaken, which will explore the impact of academic reading retreats further. The case 
study hopes to signal this developmental work to the learning development community and to contribute to discussions regarding reading as a fundamental yet under-valued academic practice, which impacts on academic analysis as significantly as writing, and which warrants closer inspection. Our research hopes to build on Lea and Street's 'other literacy practices' (2006, p.376) with a focus on the broader and the diverse disciplinary social practices of reading, thereby expanding the academic literacies perspective (Lea and Street, 1998).

\section{References}

Abegglen, S., Burns, T., Middlebrook, D. and Sinfield, S. (2019) 'Unrolling the text: Using scrolls to facilitate academic reading', Journal of Learning Development in Higher Education, Issue 14, April 2019. Available at:

https://journal.aldinhe.ac.uk/index.php/ildhe/article/view/467 (Accessed: 9 August 2019).

Brewerton, G. (2014) 'Implications of student and lecturer qualitative views on reading lists: A case study at Loughborough University, UK', New Review of Academic Librarianship, 20, pp.78-90.

Christie, H., Tett, L., Cree, V. and Mccune, V. (2014) '“It all just clicked": A longitudinal perspective on transitions within university', Studies in Higher Education, 41(3), pp.1-13.

Cottrell, S. (2013) The study skills handbook (4th ed., Palgrave study guides). Basingstoke: Palgrave Macmillan.

Fung, D. (2017) Connected Curriculum for Higher Education. London: UCL Press. Available from http://www.jstor.org/stable/j.ctt1qnw8nf (Accessed: 15 February 2018).

Grant, B. and Knowles, S. (2000) 'Flights of imagination: Academic women be(com)ing writers', International Journal for Academic Development, 5(1), pp.6-19. 
Hallett, F. (2013) 'Study support and the development of academic literacy in higher education: A phenomenographic analysis', Teaching in Higher Education, 18(5), pp.518-530.

Hannon, C., Faas, D. and O'Sullivan, K. (2017) 'Widening the educational capabilities of socio-economically disadvantaged students through a model of social and cultural capital development', British Educational Research Journal, 43(6), pp.1225-1245.

Hill, P. and Tinker, A. (2013) 'Integrating Learning Development into the student experience', Journal of Learning Development in Higher Education, Issue 5. Available at https://journal.aldinhe.ac.uk/index.php/ildhe/article/view/172 (Accessed: 9 August 2019).

Hockings, C. (2010) Inclusive learning and teaching in higher education: a synthesis of research, HEA, April. Available at https://www.lboro.ac.uk/media/wwwlboroacuk/external/content/services/cap/downlo ads/documents/HEA\%20Report\%20on\%20inclusive\%20teaching.pdf (Accessed: 9 August 2019).

Kornhaber, R., Cross, M., Betihavas, V. and Bridgman, H. (2016) 'The benefits and challenges of academic writing retreats: An integrative review', Higher Education Research and Development, 35(6), pp.1210-1227.

Lave, W. and Wenger, E. (1991) Situated learning: Legitimate peripheral participation. Cambridge: Cambridge University Press.

Lea, M. and Street, B. (1998) 'Student writing in higher education: An academic literacies approach', Studies in Higher Education, 23(2), pp.157-172.

Lea, M. and Street, B. (2006) 'The "academic literacies" model: Theory and applications', Theory Into Practice, 45(4), pp.368-377.

MacMillan, M. (2014) 'Student connections with academic texts: a phenomenographic study of reading', Teaching in Higher Education, 19(8), pp.943-954. 
Marton, F. and Säljö, R. (1976) 'On qualitative differences in learning. I - Outcome and Process', British Journal of Educational Psychology, 46, pp.4-11.

Meyer, J. and Land, R. (2003) Threshold concepts and troublesome knowledge: Linkages to ways of thinking and practising within the disciplines. ETL Project Occasional Report 4. Edinburgh. Available at http://www.leeds.ac.uk/educol/documents/142206.pdf (Accessed: 9 August 2019).

Meyer, J. and Land, R. (2005) 'Threshold Concepts and Troublesome Knowledge (2): Epistemological Considerations and a Conceptual Framework for Teaching and Learning', Higher Education: The International Journal of Higher Education and Educational Planning, 49(3), pp.373-388.

McAlpine, L. (2012) 'Shining a Light on Doctoral Reading: Implications for Doctoral Identities and Pedagogies', Innovations in Education and Teaching International, 49(4), pp.351-361.

Middlebrook, R. D. (1994) 'Instructional Benefits of Textmapping'. Available at: http://www.textmapping.org/benefits.html (Accessed: 20 February 2019).

Moore, T. (2013) 'Critical thinking: seven definitions in search of a concept', Studies in Higher Education, 38(4), pp.506-522.

Morgan, H., and Houghton, A. M. (2011) 'Inclusive curriculum design in higher education: Considerations for effective practice across and within subject areas', The Higher Education Academy. Available at https://www.advance-he.ac.uk/knowledgehub/inclusive-curriculum-design-higher-education (Accessed: 20 February 2019).

Murray, R. and Newton, M., (2009) 'Writing retreat as structured intervention: margin or mainstream?', Higher Education Research and Development, 28(5), pp.541-553. 
Papen, U. and Thériault, V., (2017) 'Writing retreats as a milestone in the development of PhD students' sense of self as academic writers', Studies in Continuing Education, 40(2), pp.1-15.

Rhead, A. (2016) '“l've written my essay... I just need to find the references to support it now": the stage as a metaphor for developing academic practices'. Keele Annual Teaching Symposium, 15 June, Keele.

Saltmarsh, D. and Saltmarsh, S. (2008) 'Has anyone read the reading? Using assessment to promote academic literacies and learning cultures', Teaching in Higher Education, 13(6), pp.621-632.

Shon, P.C. (2012) How to Read Journal Articles in the Social Sciences: A Very Practical Guide for Students. $2^{\text {nd }}$ ed. Sage Study Skills. London: SAGE.

Wallace, M. and Wray, A. (2016) Critical reading and writing for postgraduates. $3^{\text {rd }}$ ed. Sage Study Skills). London: SAGE.

Weller, S. (2010) 'Comparing Lecturer and Student Accounts of Reading in the Humanities', Arts and Humanities in Higher Education, 9(1), pp.87-106.

Wingate, U. (2006) 'Doing away with "study skills”, Teaching in Higher Education, 11(4), pp.457-469.

Wisker, G. and Robinson, G. (2009) 'Encouraging postgraduate students of literature and art to cross conceptual thresholds', Innovations in Education and Teaching International, 46, pp.317-330.

Veles, N., Carter, M. and Boon, H. (2018) 'Complex collaboration champions: University third space professionals working together across borders', Perspectives: Policy and Practice in Higher Education, pp.1-11.

\section{Author details}


Angela Rhead is a Learning Developer at Keele University and Senior Fellow of the Higher Education Academy (SFHEA) with a particular interest in academic reading practices. She has presented workshops and research findings regionally and at national conferences such as BERA, SEDA and ALDinHE. Angela convenes Keele's annual Becoming Well Read symposium and provides professional development workshops for academics and leanring developers interested in running reading retreats. 